\title{
Entrevista com Céline Ruivo
}

\author{
José Quental'
}

\begin{abstract}
Resumo
Céline Ruivo é diretora de coleções de filmes da Cinémathèque française (20II) e coordenadora da Comissão Técnica da FIAF (2016). Formada em Cinema pela Université Paris I - Panthéon-Sorbonne e doutora pela pela Université Paris 3 - Sorbonne Nouvelle, passou ainda pela Université Paris 8 (Master Válorisation du Patrimoine cinématographique et audiovisuels) e pela Selznick School da George Eastman House. Seu percurso de formação e profissional é exemplar de uma nova geração de preservacionistas audiovisuais que vêm aos poucos ocupando postos-chave nas principais instituições de guarda e conservação do patrimônio audiovisual. A entrevista foi realizada em setembro de 2018 na Cinemateca do MAM do Rio de Janeiro.
\end{abstract}

\section{Palavras-Chave}

Cinematecas; Preservação audiovisual; Digital; Formação; Patrimônio Audiovisual

\begin{abstract}
Céline Ruivo is Curator of the Cinematheque française film collection (20II) and Head of the Techincal Commission of FIAF (2016). Gradueted in cinema from the Université Paris I - Panthéon-Sorbonne and PhD by Université Paris 3 - Sorbonne Nouvelle, she alson passed by Université Paris 8 (Master Válorisation du Patrimoine cinématographique et audiovisuels)) and Selznick School da George Eastman House. Her academic and professional background is exemplary of a new generation of audiovisual preservationists who are gradually occupying key positions in the main institutions for the conservation and conservation of audiovisual heritage. This interview took place at the Cinemateca do MAM do Rio Janeiro in September 2018.
\end{abstract}

\section{Keywords}

Cinematheques; Audiovisual preservation; Digital; Formation;Audiovisual Heritage

José Quental [QQ]: Para começar, gostaria que você falasse um pouco sobre a sua trajetória, sobre a sua formação antes de começar a trabalhar com preservação de filmes.

Céline Ruivo [CR]: Antes de entrar no campo conservação, da preservação do patrimônio, eu, por muitos anos, estudei teoria do cinema na [Université] Paris I. Eu estudei teoria, e cheguei a fazer um primeiro mestrado em Estética do Cinema ${ }^{2}$. Isto foi no iń́cio dos anos 2000. E, em seguida, decidi me voltar para a questão da... Na verdade, eu já tinha uma certa curiosidade pela questão da valorização do patrimônio e eu vi que existia um mestrado sobre o tema na Université Paris 8, onde era ensinado, em primeiro lugar, sobre a valorização. ${ }^{3}$

I Doutorando em Cinema (Université Paris 8, França) com apoio da CAPES. Curador a temática preservação da Mostra de Cinema de Ouro Preto (CineOP) e pesquisador associado a Cinemateca do Museu de Arte Moderna do Rio de Janeiro (Cinemateca do MAM).

2 Université Paris I - Panthéon-Sorbonne. Master Cinéma et Audiovisuel

3 Université Paris 8 - Master Cinéma et Audiovisuel - Valorisation des patrimoines cinématographiques et audiovisuels. 
Isto é, como valorizar, divulgar um filme, como o programar. Havia mesmo um cineclube nesta universidade, onde aprendíamos a programar. $\mathrm{E}$, em segundo lugar, a grande força desse mestrado é a de que verdadeiros restauradores vinham ensinar, transmitir suas experiências em restauração, como Luciano Berriatúa, que é muito conhecido por seu trabalho de restauração dos filmes de Murnaupor exemplo4. Além disso, o primeiro ano desse mestrado se passava na França e o segundo no exterior. E nós ainda devíamos escolher um tema para a monografia final... O meu tema apareceu aos poucos, no segundo ano do mestrado, quando eu decidi dar sequência aos meus estudos em Nova lorque. Passei pelo Brooklyn College e fiz um estágio no MoMA [The Museum of Modern Art]. E foi este estágio no MoMA que me deu a ideia do tema do trabalho final, pois mudei de tema ao longo do percurso. Eu fiquei muito interessada em compreender, justamente, a relação que existiu entre Henri Langlois ${ }^{5}$ e Iris Barry 6 . Isto é: como a cinemateca do MoMa [Film Library] nasceu logo antes da Cinémathèque française, como eles se apoiaram e como tiveram juntos a ideia de criar a FIAF [Federation International des Archives du Film]. Iris Bary veio a Paris em 1937 e eles concretizaram esse grande projeto, um pouco louco, de criar a FIAF.

JQ: Apenas para voltarmos um pouco à sua relação com o cinema. Seu interesse por filmes veio antes do seu interesse pelos arquivos? Você gostava de assistir filmes? Tinha um lado cinéfila?

CR: Sim, isso mesmo. Desde a minha infância. Na televisão francesa à época, nós tínhamos muita sorte, eram exibidos muitos filmes, muitos filmes do patrimônio eram exibidos. Eu assistia Charles Chaplin ou Buster Keaton aos domingos pela manhã. Havia emissões especiais de Cinema nas noites de terça-feira na Troisième chaine. Eu assistia muitos filmes americanos de época, como Hitchcock. Todos dublados em francês. Filmes de faroeste, pois meu pai adora os faroestes de John Ford. Então tudo isso fez parte da minha primeira cultura. E, evidentemente, depois, ficando mais velha... Paris é, de todo modo, "A" capital do cinema, onde há filmes passando durante o dia inteiro. Aos poucos, eu fui me tornando uma verdadeira cinéfila. $\bigcirc$ Quartier Latin se tornou minha segunda casa, onde eu ia assistir filmes todos os dias, quando era estudante. Ainda no colégio eu fiz uma formação. Havia uma preparação para o Baccalauréat ${ }^{8}$ em cinema.

JQ: Então, após a passagem pela Université Paris 8 onde você realizou esse mestrado sobre a relação entre a Cinémathèque française e a Film Library do MoMA...

CR: Isso, eu fiz essa pequena monografia e também um relatório de estágio

4 Luciano Berriatúa é um importante historiador do cinema e restaurador de filmes. Grande especialista na obra de F.W. Murnau, restaurou, entre outros, Nosferatu (1922), versão de 2006. Colabora regularmente com a Filmoteca Española e com o Murnau Stiftung.

5 Henri Langlois (19/4-1977) foi o fundador da Cinémathèque française (1936) e personagem central da história da preservação cinematográfica. Diversos artigos e livros abordam a trajetória de Langlois e a história da Cinémathèque française, entre outros: Olmeta (2000); Barbin (2005); Mannoni (2006); Paini (20I4). Neste dossiê ver o artigo de Stephanie-Emmanuelle Louis.

6 Iris Barry (1895-1969) foi a fundadora da Film Library do MoMA (1935). Entre outros ver: Wasson (2005) e Sitton (20I4).

7 A FIAF foi criada em Paris em 1938. Quatro arquivos de filmes participaram de sua fundação: Cinémathèque Française, Film Library do MoMA, National Film Library do British Film Institute e Reichfilmarchiv. 8 Equivaleria ao vestibular no Brasil. 
sobre o as atividades que fiz no serviço de programação do MoMA. E, em seguida, eu descobri que havia uma formação mais prática... eu comecei a procurar uma formação mais prática, pois o mestrado da Paris 8 era bom, mas não havia prática o suficiente.

JQ: É uma formação muito teórica...

CR: Sim, muito teórica. Então, buscado eu descobri que a Selznick School ${ }^{9}$ em Rochester oferecia um curso de um ano de teor muito prático. Eu me disse: bom, terminando esse estágio no MoMA, eu vou tentar essa formação na Selznick School e fico um ano a mais nos Estados Unidos. Então fui morar em Rochester. Eu terminei o mestrado, me organizei e parti para os EUA.

JQ: E como foi essa nova formação? Você encontrou esse lado da prática em preservação que você buscava?

CR: Sim, eu penso que ela é uma formação muito profissionalizante neste sentido. Isto é, nós aprendemos todos os aspectos do manuseio de filmes nitrato ${ }^{10}$, acetato" e toda a história da técnica que segue colada. $\mathrm{Na}$ verdade, a prática acompanha a teoria. Desta forma a história das técnicas é algo muito presente no ensino da Selznick School e isto está muito ligado à figura de Paulo Cherchi Usai ${ }^{12}$ que fundou a escola.

JQ: Ele (Paulo Cherchi Usai) ainda estava lá nesse momento?

CR: Não, ele não estava mais lá. Ele já tinha partido para trabalhar na Austrália $^{13}$. Quem dirigia a escola era Patrick Loughney que tinha vindo da Library of Congress. $\mathrm{E}$ bom, o fato é que muitos profissionais dos arquivos passavam para nos ajudar a compreender a história da conservação de filmes, a aprender sobre os padrões de conservação, sabre a gestão e o armazenamento nas reservas de filmes etc. De verdade, isso unificava muito bem a prática e a teoria. $E$, ao final, nós tinhamos um projeto pessoal para realizar durante três meses. Eu escolhi trabalhar com a coleção de filmes mudos franceses que eles possuíam, em particular com os filmes da Socièté Gaumont ${ }^{14}$. É muito interessante, pois eles possuem coleções riquíssimas tanto em nitrato quanto em acetato. Uma coleção de aparelhos muito interessante também. Eu senti que essa formação me colou no trilho, me ajudou a compreender como funciona uma restauração, o processo de restauração. Isso me apaixonou, e eu vi que estava realmente afim

9 L. Jeffrey Selznick School of Film Preservation da George Eastman House.

10 "Termo genérico utilizado para as películas em base de nitrato de celulose. Foi o primeiro material plástico moderno a ser utilizado, quase universalmente, como suporte dos filmes $35 \mathrm{~mm}$ até os anos de 1950". (Coelho; 2009).

II "Plástico derivado da celulose utilizado para o suporte do filme cinematográfico. Há mais de um tipo de acetato utilizado pelo cinema: diacetato de celulose, acetato-propionato, acetato-butirato e triacetato de celulose (...) Sob o nome de "filme de segurança" (safety), os acetatos de celulose substituíram as películas de nitrato". (Coelho; 2009).

12 Paolo Cherchi Usai é um dos principais especialistas em patrimônio cinematográfico no mundo. Foi um dos fundadores, Giornate del Cinema Muto de Pordenone) na Itália (1982) e da L. Jeffrey Selznick School of Film Preservation da George Eastman House (1996) ao lado de L. Jeffrey Selznick (1932-1997). É autor entre outros dos livros : Silent cinema: an introduction (2000) e The death of cinema: history, cultural memory, and the digital dark age (200I).

13 No National Film and Sound Archive of Australia.

14 Fundada em 1895 é companhia produtora de filmes mais antiga em atividade. 
de me direcionar para as profissões ligadas ao trabalho de restauração de filmes.

JQ: Neste ponto você já havia definido o que gostaria de fazer no futuro? Isto é, trabalhar com arquivos de filmes, com restauração...

CR: Sim, eu sentia que era algo que me entusiasmava bastante...

JQ. E depois você foi buscar o que? Eu te pergunto isso, pois, este é um problema que parece existir neste campo. Começamos a ver o aparecimento de algumas formações em restauração, outras mais voltadas para os arquivos e a conservação de filmes. Diversas formações começam a ser criadas, particularmente a partir dos anos de 1990 e início dos anos 2000, como esta da Paris 8 , a de Amsterdam ${ }^{15}$, de Rochester... Mas, um dos grandes problemas é o depois... é: como o profissional formado consegue encontrar um posto de trabalho no mundo dos arquivos. Não é tarefa fácil. $O$ que você pensa disso?

CR: Realmente é um mundo pequeno. No meu caso parecia haver dois caminhos: fosse trabalhar nos arquivos, fosse em empresas privadas. E, efetivamente, esta foi a primeira coisa que eu fiz. Saindo da minha formação na Selznick School eu consegui um posto no Laboratório Éclair. Lá eu pude completar minha formação indo trabalhar com o digital, pois naquele momento, a Selznick era ainda muito restrita nesse nível. Eu possuía um conhecimento do processo fotoquímico bastante bem consolidado e avançado, pois havíamos visitado diversos laboratórios nos EUA, como o laboratório da Library of Congress. Passamos bastante tempo com técnicos. Na Éclair, eu pude reforçar meus conhecimentos e, sobretudo, aprender bastante sobre o digital, sobre a cadeia do digital. E talvez, quem sabe, ter ajudado na sensibilização dos técnicos daquele laboratório sobre os aspectos da manipulação de objetos de arquivo. Pois lá isso era algo ainda novo. Naquela época, o verdadeiro precursor na restauração de filmes de arquivo era Jean-Pierre Neyrac. Ele tinha seu próprio laboratório que fora comprado pela Éclair. Neyrac era uma espécie de entidade em si mesmo. E a Éclair entrou neste campo de restauração digital de arquivos. Mas, quando a Éclair recebia materiais em nitrato, por exemplo, ela não sabia o que fazer com aquilo.

JQ: Isso foi em que ano?

CR: Isso foi em 2007, 2008. Eu me dei conta de que quando eles recebiam filmes em nitrato, na medida do possível Neyrac lidava com esses filmes, pois os técnicos da Éclair só tinham por habito trabalhar com pós-produção do que se chama "filme fresco". Os "filmes frescos" são as novas produções. Porém, dos filmes velhos, como eles mesmos diziam, eles não entendiam nada: as questões de manipulação de película antigas, como o nitrato, ou até mesmo questões de formatos obsoletos. Então, eu me dei conta de que eu... mesmo que eu tenha sido formada em muitas coisas, eu também acabei formando-os para trabalhar com materiais que chegavam e eles não conheciam nada. Era preciso estar ali e dizer: cuidado! Esse filme é frágil, é preciso observar que há encolhimento ${ }^{16} \ldots o$ encolhimento é algo importante.... Então era isso, foi efetivamente uma troca entre

15 Mestrado intitulado Preservation and Presentation of the Moving Image (Heritage Studies).

16 "Processo de redução das dimensões de uma película cinematográfica produzido pela perda de umidade ou plastificante e/ou pela degradação estrutural do suporte. Pode reduzir as dimensões de uma película tanto na sua largura quanto no seu comprimento". (Coelho; 2009) 
mim e a Éclair que não deixou de ser interessante. Eu estabelecia contato com os detentores de direito... mais com detentores de direito do que com arquivos na verdade. $E$ é verdade que é um mundo bastante duro... Um mundo onde a ética não entra muito em discussão.Algumas vezes havia situações com os clientes que... bom... eram as escolhas dos clientes. Mas, uma coisa que me inspirou muito, e que eu adorei fazer, foi quando Gaumont decidiu restaurar French Cancan de Jean Renoir (1954). Isso foi bem central, pois este foi um dos raros filmes franceses em Technicolor ${ }^{17}$ que a Gaumont quis restaurar. $E$ isso me interessou muito, pois, de início [o negativo da] separação em três cores não se encontrava na França, estavam sem paradeiro. Então a Gaumont disse simplesmente: nós temos um velho internegativo Eastmancolor largado em nossa reserva técnica e vamos utilizá-lo para a nossa restauração - Naquele momento as restaurações ainda estavam sendo feitas em $2 \mathrm{~K}$. O $4 \mathrm{~K}$ ainda era muito raro - Vamos fazer nossa restauração $2 K$ com nosso velho internegativo Eastmancolor. Internegativo este, que já estava completamente desbotado. Neste momento eu intervim, pois, em primeiro lugar, o tema me interessava, e eu disse que não era possível.A separação em três cores não podia ter desaparecida, ela devia estar em algum lugar. Bastava que a gente tentasse compreender como o filme foi revelado à época. Vimos que o laboratório Technicolor francês só foi inaugurado depois da filmagem do filme de Renoir em 1955. Até então, aqui na Europa, a tricromia só existia na Inglaterra até aquele momento. Então eu encontrei a pista da tricromia, das três separações, na Inglaterra. Nesse momento eu disse a Gaumont: temos que escrever seja para o Laboratório - que já não mais existia - , seja para o BFI (British Film Institut). Mas o que foi muito estranho foi que, de início, o BFI não quis dizer que eles tinham o material do filme. Isso foi muito, muito estranho.

JQ: A velha questão dos arquivos...

CR: Isso. Estava um pouco escondido. Uma coisa levou a outra, e a Gaumont me passou velhos dossiês que eles tinham, onde constava um inventário do BFI que mostrava que eles tinham ao menos umas 200 latas do filme. Bom, 200 latas de um filme, faz sentido para a tricromia. Então, insistindo [com o BFI] eles acabaram pedindo desculpas, dizendo que o material não estava bem catalogado nas bases de dados. Por meio disso, por meio das pesquisas que eu pude realizar, nós pudemos trazer para a França todos os negativos originais de French Cancan que estavam na Inglaterra. Junto com as copias originais feitas por imbibition ${ }^{18}$. Isso foi muito importante também, pois da mesma maneira, eu precisei convencer a Gaumont e o técnico de correção de cor que elas deveriam ser utilizadas para recriar o Technicolor. Não apenas para fazer uma coisa "legal”, mas para termos uma base de referência. Evidentemente a Gaumont entrou com uma perspectiva comercial. Por um lado, eles se inspiraram da cópia de referência ${ }^{19}$ que existia, e por outro fizeram coisas muito comerciais para satisfazer um grande público e lançar um Blu-ray. Para mim trata-se de uma restauração interessante, mas cujo resultado não é tão fiel quanto poderia ser ao Technicolor.

JQ: Então você viveu um momento bastante singular, bastante especial na Éclair,

17 Processo norte-americano de cinema em cores que utiliza uma separação em três negativos estabelecido no final dos anos de 1930 e não mais utilizado a partir dos anos de 1960. [Le Roy, 20I I].

18 Método de copiagem mecânico no qual a imagem é formada por uma impressão de filme a filme como o utilizado no Dye Transfer do processo Technicolor. (FIAF)

19 Dye transfer. 
não? Um momento de transformação do laboratório, dessa passagem para o digital. Se não me engano é nesse momento que a Éclair desenvolve o Nitroscan, não é? Um momento onde eles investem muito no digital, com Christian $\operatorname{Lurin}^{20} \ldots$

CR: Sim, exato. O Nitroscan foi também um projeto no qual Neyrac estava envolvido, pois [seu laboratório] pertencia a Éclair. A ideia foi a de recuperar o projeto do scanner que tinha sido desenvolvido para o CNC, que se chama Sacha. O Sacha é um scanner criado em 1997/1998. ${ }^{21}$ E o projeto deste Scanner foi reutilizado. O pedido foi direcionado para o criador do Sacha. Eles compraram esse projeto, a patente do projeto, e elaboraram o Nitroscan que podia trabalhar até a resolução de $4 \mathrm{~K}$. Trata-se de uma maquina maravilhosa, pois ela poder escanear qualquer formato [de filme], do 8 ao $70 \mathrm{~mm}$, ou mesmo ao $90 \mathrm{~mm}$, sem utilizar as perfurações e podendo fazer também a imersão ${ }^{22}$. Este era um problema da Éclair à época, que era de escanear tudo à seco. $O$ trabalho de limpeza [digital] dos filmes levavam semanas inteiras, que eram muito caras e, às vezes, podiam ser muito destrutivas. Quando queremos limpar velhos nitratos... com certos algoritmos, bem honestamente, o resultado pode ser bastante desapontador. A imersão não é destrutiva, não chegaria a dizer natural, mas é um processo de apagamento das alterações do tempo bem menos invasivo, mais respeitoso ao filme do que as horas de restauração na palheta.

JQ: Bom, após este trabalho na Éclair, você chega a Cinémathèque française?

CR: Não exatamente, há um pequeno intervalo. French cancan me inspirou bastante e eu decidi dar continuidade com um doutorado. Um doutorado sobre o Technicolor. Eu me inscrevi na [Université] Paris 3 e na época... Bom, eu estava muito contente com o trabalho que eu tinha desenvolvido na Éclair, mas eu achava que precisa de novos desafios. Eu tinha o desejo de escrever sobre o Technicolor, e mais precisamente, em ir mais a fundo nessas pesquisas. TrabaIhando com French cancan eu tive consciência de que me faltavam muitas coisas: informações, aspectos do processo técnico... E eu quis fazer isso. Me inscrevi na Paris 3 e tomei a decisão de tirar um ano sabático para poder realizar minhas pesquisas nos EUA. Como se tratava de um processo nascido nos EUA, me parecia lógico de ir pesquisar certos fundos arquivísticos. A George Eastman House tinha adquirido os fundos de arquivo da Technicolor, dos laboratórios Technicolor. Eu comecei minhas pesquisas por lá, em seguida pesquisei na Library of Congress onde pude ver mesmo os seus originais, as cópias Technicolor originais que eles possuem. Fui também à Los Angeles consultar certos fundos de documentos em papel relativos à Technicolor. Foi isso, uma grande viagem que eu fiz e que me permitiu aprofundar meus conhecimentos sobre o Technicolor.Ainda que houvesse muitas coisas já escritas, existiam certas coisas que eu queria

20 Especialista em restauração, trabalhou na Kodak (I985-2006), aboratório Éclair (2006-20I3) e Technicolor (2013-2016). No ano de 2002 ganhou um prêmio "Scientific and Engineering » da Association of Motion Pictures Arts and Sciences responsável pelo Oscar.

$21 \mathrm{Na}$ verdade, em 2004. Para mais detalhes ver Comte; Riccordel (2004).

22 O processo de imersão ou Janela molhada (wet-gate): "Dispositivo instalado nas copiadeiras para minimizar que uma duplicação copie os riscos físicos do original, especialmente dos localizados no suporte. A película original passa por uma janela submergida ou recoberta com um líquido de índice de refração idêntico ao da película que preenche os riscos e reduzem seu efeito visível nas reproduções". (Coelho; 2013) 
precisar, que eu queria desenvolver..$^{23}$

JQ: Isso em 2010?

CR: Eu parti em 2010 aos EUA e vivi em Washington D.C.

JQ: Então em seguida você teve a possibilidade de se candidatar a vaga na Cinémathèque française.

CR: Isso. Havia essa vaga que se abriu na Cinémathèque française. Eu ainda estava nos EUA. Eu decidi me candidatar e eu comecei em $201 \mathrm{l}$.

JQ: Você se imaginava trabalhando na Cinémathèque française? $O$ que ela representava para você? Digo, como cinéfila, estando, depois de alguns anos, trabaIhando no meio dos arquivos, dos laboratórios e restaurações.

CR: Era um sonho! Para mim foi um sonho! Eu tinha feito meu trabalho de mestrado sobre Henri Langlois, eu me interessava pela história da Cinémathèque. Sabemos que a ela é o berço de formação da nossa cinefilia na França. A gente sabe. Para mim simbolicamente, historicamente, entrar para a Cinémathèque française tinha uma lógica. Enfim, era um sonho. $E$, além disso, ter toda essa responsabilidade eu sentia como um enorme desafio. Eu estava queimando algumas etapas, estava indo diretamente ao posto de Diretora de Coleções, sem ter trabalhando antes na Cinémathèque, sem ter, nem mesmo, pelo menos oficialmente, trabalhado em um arquivo.

JQ: Você já conhecia a Cinémathèque por dentro? Tinha alguma relação com os arquivistas, com os funcionários?

CR: Não especialmente. Eu tinha visitado Saint-Cyr ${ }^{24}$, eu sabia mais ou menos o que eram (os arquivos da Cinémathèque). Mas, não, não especialmente.

JQ: Você não sentia um pouco de medo? No sentido da história da Cinémathèque française, de um certo peso da história.A figura de Langlois, a história problemática da conservação de filmes na instituição. Assumir o posto de diretora da coleção de filmes..

CR: Dava um pouco de medo. Eu tinha lido muitos textos que havia escrito Laurent Mannoni ${ }^{25}$. Para mim Mannoni é umas principais figuras da história das técnicas, de diferentes histórias do cinema e eu estava muito contente de poder trabalhar em colaboração com ele. Até por que, quando eu estava na Selznick School eu havia trabalhado sobre muitos procedimentos Gaumont, como o Chronochrome, que era um procedimento de tricomia. A questão da cor sempre me fascinou. E, estar com Laurent Mannoni que conhecia bem os filmes Gaumont, a história das técnicas do cinema, era muito bom para mim. Era um desafio. E eu fui contratada, é preciso reconhecer isso, porque, claro eu tinha

23 Em 2016 Ruivo defendeu a tese intitulada "Le Technicolor trichrome : histoire d'un procédé et enjeux de sa restauration" sob a orientação de François Thomas.

24 As coleções fílmicas da Cinémathèque française são armazenadas no antigo forte de Saint-Cyr.

25 Diretor de Patrimônio da Cinémathèque française. Autor, dentre outros, dos livros:"A grande arte da luz e da sombra"(2003) e "Histoire de La Cinémathèque Française" (2006). 
feito um trabalho sobre Langlois e a história da Cinémathèque, mas, sobretudo, porque eu tinha essa formação nas tecnologias digitais. A Cinémathèque precisava muito de pessoas que tivessem uma expertise sobre esse tema. Eu reconheço isso, foi isso que me fez ser escolhida nessa seleção. $\mathrm{Na}$ época ainda faziam digitalização em $\mathrm{Beta}^{26} \ldots$

JQ: Qual foi o quadro que você encontrou nos arquivos da Cinémathèque? Qual foi o trabalho que você passou a desenvolver lá? Quais foram as metas, os desafios estabelecidos?

CR: Acho que os grandes desafios foram, por um lado estabelecer uma cadeia de restauração digital e, por outro lado, estabelecer uma cadeia de conservação de arquivos digitais. Desde que eu cheguei, eu quis realmente renovar, reposicionar a Cinémathèque sobre esse tema. Não era mais possível conservar os filmes em Beta, era preciso mudar de estratégia, sistematizar a arquivamento de documentos digitais. Mesmo sem fazer uma digitalização muito ambiciosa, ao menos fazer o mínimo sobre a questão da resolução, para que fosse utilizável... $\mathrm{Na}$ Éclair a resolução HD era uma evidência à época. Em 201 I não havia ainda HD na Cinémathèque, era preciso atualizar isso para pequenas digitalizações. Atualizar a cadeia para trabalhar com o $2 \mathrm{~K}$, arrumar a cadeia para a transcodificação, para termos os arquivos de difusão, os arquivos de projeção. Tudo o que a Cinémathèque não possuía à época. Realmente não existia uma perspectiva global. Para mim, era preciso criar essa visão englobante e formar as pessoas para essa nova cadeia, pois os documentalistas não conheciam nada desse universo, era um mundo desconhecido. Era preciso colocar em prática uma cadeia de arquivamento, mesmo que não fosse perfeita, ela não é perfeita hoje, mas que fizesse diferença entre um arquivo de conservação, um arquivo de difusão. Eu acho que eu consegui fazer isso, mas em relação a conservação digital esta continua sendo um problema, nesse ponto não há nada resolvido. Colocamos as coisas em $\mathrm{LTO}^{27}$, mas a partir do momento em que você não tem verdadeiros robôs para, regularmente fazer as migrações...Você faz manualmente, mas é um processo devorador de tempo. Fazer isso manualmente não é possível. Mas de toda forma, esse é um tema que precisa ser enfrentado com o auxílio do CNC [Centre National de Cinématographie]. É o CNC quem pode agir sobre esse tipo de assunto, o que não fez ainda, e a Cinémathèque depende do CNC financeiramente. A gente não pode comprar um robô de LTO...

JQ: Os arquivos digitais da Cinémathèque são conservados em que local?

CR: São conservados internamente. No servidor da Cinémathèque os arquivos leves. Nos servidores nós não colocamos os DPX. Estes estão nos nossos $\mathrm{LTOs}^{28}$. Mas o problema é esse. Eu peço para os laboratórios para guardarem uma cópia no LTO deles, mas não são todos que o fazem. Tentamos manter arquivos espelhados nos laboratórios e de ter arquivos em nossa sede. É isso, nos nossos servidores são apenas os arquivos de difusão: os DCPs, ProRes...A gente

26 Betacam

27 Linear Tape-Open é "uma tecnologia de armazenamento de formato aberto desenvolvida conjuntamente pela Hewlett-Packard (HP), a International Business Machines (IBM) e a Seagate (...) é o formato dominante usado na indústria cinematográfica". (Science and technology council of the academy of the motion pictures arts and sciences; 2009, p.32)

28 Hoje a Cinémathèque française utiliza fitas LTO 6. 
não conserva os DPX, arquivos pesados no servidor.

JQ: Essa transição digital na França possui suas particularidades, não? O CNC, de uma certa maneira decidiu não encarar de frente essa transição, no sentido de criar uma infraestrutura de conservação digital. Mesmo tendo elaborado o Plano de Digitalização de Obras do Patrimônio, ${ }^{29}$ a decisão foi de estabelecer o retorno em película, de continuar conservando os filmes em película. Mas e os arquivos digitais gerados nesse processo? O que fazer com eles?

CR: Isso, exatamente. Existe aí um hiato, uma falta no momento presente... Não se trata de criticar... Mas, o CNC esta muito atrasado nesse aspecto. Eles tentaram encontrar uma solução, mas uma solução sem discutir com a gente, que seria a de contratar um serviço privado para fazer esse tipo de armazenamento, de migração e de verificação regular dos arquivos, de forma automática. O grande problema disso é que - O EYE Filmmuseum, por exemplo, fez esse tipo de escolha - quando se contrata esse serviço de uma sociedade privada, se um dia ela fechar as portas, todos os arquivos ficam presos nela e nós não os recuperamos. O Eye Filmmuseum teve esse problema. No início do seu grande projeto que se chamava Images for the future 30 eles possuíam um contrato com uma empresa nos Estados Unidos que fazia apenas isso: fazia o armazenamento, conservação, transcodificação. Incrível, no papel era genial, eles faziam tudo,tudo o que o EYE Filmmuseum precisava. Mas, acontece que a empresa fechou. $O$ que você faz nesse caso? Não sei quantos Terabytes de arquivos, como repatriar todos esses arquivos? Eu não sei como... Então quando o CNC nos apresenta esse tipo de solução, a gente diz calma. Nós somos, de toda forma, pagos para fazer isso. Fazer o deposito como a gente faz dos nitratos no CNC, em uma empresa privada? E se um dia ela fecha... Eu digo, não sou contra, mas vou guardar sempre uma cópia na Cinémathèque, em LTO. Mesmo que seja um sistema $B$, eu guardo mesmo um sistema B. Hoje na França, me parece que uma instituição que vem fazendo um trabalho muito bom de conservação de arquivos, mas não arquivos audiovisuais, é a Bibliothèque National de France. Eles possuem soluções extremamente elaboradas, criadas internamente. $O$ que quer dizer que é público, que continua um arquivo público. Ainda que tenha dificuldade de gerenciamento dos arquivos, ao menos nós estamos seguros que não ficaremos encurralados como num caso de uma empresa privada que encerra suas atividades. Depois é preciso encontrar os meios de fazer progredir as tecnologias e fazer sua própria manutenção. Mas é preciso internalizar. Ao menos essa é minha concepção. Os laboratórios fecham. Quando um grande laboratório como o LTC fechou ${ }^{31}$, nós sabemos o que aconteceu: todos os arquivos dos produtores ficaram presos no laboratório. E mesmo alguns técnicos sabotaram deliberadamente. Durante alguns dias houve um grande pânico, pois, todos os arquivos de grandes produções ficaram presos nos servidores da LTC. E eles [os técnicos] disseram: Não! Nos despediram da noite para o dia, os arquivos ficam no servidor e só a gente sabe como recuperá-los. Isso é o digital. Não podemos buscar um filme na estante. Nesse aspecto nós estamos muito atrasados.

29 Política de financiamento para a digitalização e restauração de filmes do patrimônio cinematográfico francês, que previa no prazo de 10 anos a digitalização de cerca de 10 mil filmes.

30 Projeto de digitalização realizado entre 2007 e 2014 por um consórcio de instituições de preservação da Holanda.Ver: http://www.beeldenvoordetoekomst.nl/en.html

31 No final de 2011, os laboratórios LTC, criado em 1935, e pertencente ao grupo Quinta, encerrou suas atividades e despediu todos os seus funcionários. 
JQ: Depois de quase sete anos como diretora de coleções filmes da Cinémathèque française, você sente o peso da instituição, da História da Cinémathèque? Você sente a presença do "fantasma de Langlois"? No sentido do peso dos segredos tão presentes na histórias das cinematecas. Estaríamos vivendo o fim da era dos segredos nos arquivos?

CR: A Cinémathèque sempre foi muito forte na valorização. Ela foi, como eu dizia a pouco, esse berço da cinefilía que permitiu revalorizar o cinema mudo ou o trabalho muito contemporâneo de cineastas... Langlois foi quase um produtor de filmes. Foi a Cinémathèque que produziu um filme como Rabbit's Moon de Keneth Anger (1950). Com dinheiro público! Ao mesmo tempo Langlois foi o primeiro, ou um dos primeiros, a preservar o cinema de patrimônio, e ele também inspirou as pessoas, os cineastas... e esse trabalho de inspiração promovido pela Cinémathèque française continua. Talvez, nessa influência, a face oculta do espelho, é a questão da conservação. Isto é, hoje, e isso não é nenhum segredo, nossos métodos de conservação não são suficientemente padronizados, nossas condições de armazenamento não são boas o suficiente, estamos num forte onde há muita umidade. Essas condições colocam problema para o longo prazo. Esse é um pouco o problema que foi sempre o principal da Cinémathèque française. Há o lado de mostrar e valorizar. Mesmo que a conservação tenha sempre existido, ela nunca foi suficientemente padronizada. Ela nunca entrou numa política global da instituição. O problema é, desde sempre, presente. É uma espécie de tradição negativa. Sobre a questão do segredo, do segredo de coleção... nós temos ainda os nossos segredos, eles seguem lá. Para o melhor e para o pior. Há coisas que eu gostaria bastante divulgar, de vulgarizar para empregar o termo utilizado anteriormente.Ainda que a gente cumpra um papel científico relevante na forma de apresentar e discutir a história do cinema - são muitos textos produzidos pela Cinémathèque, ela teve sua própria revista, suas próprias edições ou com o Conservatoire des techniques, que eu acho maravilhoso, uma das grandes ações que fazemos - , talvez seja preciso que esta força, que esta história, que a força da transmissão seja estimulada, que a gente consiga um trabalho de valorização ainda mais consequente. É isso que a gente tenta fazer com a nossa sessão Fenetre sus les collections ${ }^{32}$. Vulgarizar um pouco o trabalho dos arquivos de filmes. É isso que eu sempre falo para os arquivistas que vêm apresentar os filmes: aqui a gente precisa falar diretamente sobre o trabalho que que a gente faz. Nós não somos programadores, esta não é nossa profissão. Esta é a ocasião de apresentar o que fazemos.

JQ: Quem teve a ideia do Fenetre sus les collections? Foi sua? Veio da equipe? O que eu acho mais interessante nessa programação é que, de certa forma, vocês conseguiram inverter a lógica da programação da Cinémathèque - na qual os programadores vinham buscar no arquivo os filmes para compor determinado projeto - ao colocar o Arquivo indo em direção a programação.

CR: A ideia foi de Serge Toubiana ${ }^{33}$. Eu o agradeço. Isso foi, possivelmente, no

32 Programação mensal da Cinémathèque française no qual são exibidos unicamente filmes pertencentes a coleção da instituição. Em geral as sessões são apresentadas pelos arquivistas responsáveis pela conservação, restauração e tratamento desses materiais.

33 Crítico de cinema, foi redator-chefe da revista Cahiers du Cinéma (1981-1991) e diretor da Cinémathèque française entre 2003 e 2016. 
último ano em que ele estava a frente da Cinémathèque. $A$ ideia, remete um pouco as conversas, as reuniões que tivemos. Jean-François Roger, diretor de programação, tem grandes projetos de valorização, mas que são, em geral, monográficos. Isto é, fazemos, sobretudo, mostras monográficas na Cinémathèque. Nós valorizamos um cineasta. Isso pode utilizar nossa coleção, mas não necessariamente. Dentro desta política, nós tínhamos muitos filmes impossíveis de serem programados: filmes mudos, curtas-metragens, burlescos, muitas e muitas coisas que ficavam invisíveis. Nós nos demos conta que a gente acabava programando esses filmes invisíveis no estrangeiro, mas nunca em nossa própria casa. Então era essa a ideia inicial, de nos dizer, bom é o momento de programarmos na Cinémathèque française esses fundos. São, afinal, a riqueza de nossas coleções. Fazer, por exemplo uma programação sobre o cinema científico, de ter ideias temáticas que toquem a história das nossas coleções, nossas coleções históricas. É uma bela ideia e isso nos permite termos uma pequena plataforma para apresentar ao mesmo tempo nossos filmes e nosso trabalho. Isso valoriza também as equipes que trabalham nos fundos e coleções da Cinémathèque.

JQ: Chegando ao final dessa entrevista. Em 2016 você se tornou Coordenadora da comissão técnica da FIAF. Como você percebe essa missão? Como você percebe o papel da FIAF hoje?

CR: O interesse do Comitê Executivo da FIAF e de Christophe Dupin ${ }^{34}$, era o de constituir um verdadeiro grupo de trabalho. Isso estava faltava um pouco na comissão. Ainda que meu predecessor, David Walsh, tenha feito um trabalho extremamente importante. Ele publicou diversos textos pela comissão técnica, mas faltava um pouco um trabalho de grupo. Faltava uma união de esforços e uma união de conhecimentos que possuem as diferentes cinematecas. Este é um pouco meu projeto. $\mathrm{Na}$ verdade, eu não sou ninguém aí. Meu papel é o de conseguir coordenar os saberes e experiências dos diferentes membros e tentarmos estabelecer textos de referência, de tentar padronizar, ou pelo menos de encontrar uma norma FIAF. Normatizar alguns conceitos através de uma “olhar FIAF". Isso significa por exemplo, definir quais são os melhores meios hoje para a conservação de arquivos digitais ou as boas práticas para escanear filmes, etc. De conseguir tornar isso acessível e compreensível à um público mais amplo. Eu espero poder publicar em breve um texto sobre a comissão. Eu estou escrevendo um texto sobre a história da Comissão Técnica. Desde o início a missão da Comissão técnica era esse de reunir os diferentes conhecimentos técnicos de uns e de outros, e os padrões da indústria. E quem sabe, conseguir estabelecer textos de referência, de metodologia de conservação, de restauração. E a referência não é necessariamente a indústria. É ela que estabelece o padrão, mas depois é preciso entender esse padrão - não temos escolha. O DCP ${ }^{35}$ é uma criação da indústria. Mas a questão do DCP não criptografados não é da indústria, são dos arquivos. É preciso conseguir estabelecer normas de trabalho, referências que sejam verdadeiramente éticas, que respeitem uma ética dos arquivos, da conservação. É isso que a gente vem tentando estabelecer. Nós escrevemos recentemente o Digital Statement ${ }^{36}$, que é, de certa forma, um

34 Administrador sênior da FIAF.

35 Digital Cinema Package: conjunto de arquivos em conformidade com as especificações da $\mathrm{DCl}$ que contêm todos os elementos necessários (imagens, som, legendas, etc.) para a projeção de um filme. As imagens em um DCP são comprimidas utilizando codificação JPEG2000, e podem ser criptografados.

36 The Digital Statement. Recommendations for digitization, restoration, digital preservation and access. 
processo de vulgarização. Nós não temos a pretensão de dizer: nós vamos dar informações que ninguém conhece. Nossa intenção é de fornecer informações legíveis e compreensíveis para arquivos que possuem mais dificuldade, que não possuem determinado conhecimento. $O$ digital coloca questões muito amplas, utiliza termos muito técnicos que os especialistas muitas vezes conhecem, mas os conservadores não. O problema é este, são "os" conservadores que devem estruturar uma política de conservação, e eles precisam entender o que eles estão fazendo. Pois se eles não compreendem nada, não será o técnico que vai fazer política. Então é realmente necessário ter textos de referência para eles. Para que o conservador possa explicar uma decisão de compra de um scanner, para que ele possa dizer que determinado escâner faz isso ou aquilo. Mas que ele não diga que isso é fazer conservação. Para que consiga explicar precisamente a diferença entre conservação e difusão. Existem scanners que são feitos para difusão, o que não quer dizer que seja um scanner ruim, apenas que ele foi pensado para essa finalidade. Mas se você precisa conservar arquivos de boa qualidade, se o seu trabalho é mesmo um trabalho de conservação, é preciso refletir sobre o scanner que você vai utilizar. Essa é uma primeira etapa. Existem muitas outras, sobre as quais nós vamos escrever. Mas este primeiro texto, o objetivo é de vulgarizar os conhecimentos técnicos para que sejam compreensíveis para as pessoas que tomam as decisões de orçamento, que decidem uma política. Eu espero, por exemplo, que meu diretor lerá o Digital Statement em francês, pois ele também foi publicado em francês. São coisas assim que a gente tenta tornar acessível para todos. Esta é minha visão. Talvez a pessoa que venha a me substituir tenha um entendimento diferente. Mas, eu acho que é uma questão importante. Quando nós temos pequenos arquivos na África, na Índia...Arquivos que não tem muito dinheiro, mas que conseguem finalmente ter a possibilidade de investir em alguma coisa, é preciso que eles tenham as ferramentas para compreender as escolhas que vão fazer. Eles precisam poder fazer suas escolhas com toda consciência e não apenas por que um prestador de serviços diga que determinado escâner é genial. Afinal, todos [os prestadores] vão te dizer isso, todos têm um super escâner. Neste momento, eu acredito, a FIAF deve intervir e dizer: esse escâner te permite fazer isso e não aquilo. Se você tem um filme no qual a cor é um elemento essencial, você não poderá fazer uma reprodução de alto nível com esse escâner. No limite isso não será possível. São coisas que a gente precisa conseguir falar sem nos tornamos oponentes dos consultores de escâner. Não é essa a questão. Não se trata de criar inimigos. Nossa próxima etapa será o processo de conservação de arquivos. $\mathrm{Na}$ visita que fiz a universidade de Niterói ${ }^{37}$ teve algo interessante pois havia uma pessoa da Sony, que esteve também em Ouro Preto ${ }^{38}$, com quem nós discutimos as possibilidades de conservação em discos, uma solução que tem seu interessante. Isto porque o mundo do LTO que temos hoje... O LTO não é um sistema a longo prazo. É quase um suicídio coletivo. Nós estamos todos cometendo suicídio com o LTO. Pois foi um sistema imposto pela indústria. Nós o absorvemos, nós o utilizamos, mas precisamos encontrar um outro sistema, outro caminho. Pois este é um suicídio. É o fim do patrimônio cinematográfico.

A primeira parte deste documento foi publicada em 2018. Acessivel em: https://www.fiafnet.org/pages/E-Resources/Digital-Statement.html

37 Visita ao Laboratório Universitário de Preservação Audiovisual da Universidade Federal Fluminense coordenado pelo professor Rafael de Luna Freire.

38 Durante a Mostra de Cinema de Ouro Preto de 2018 foi organizada uma mesa com representantes da industria e do mercado audiovisual, entre os quais Erick Soares da Sony. 
JQ: Você acha que a indústria possui hoje a capacidade de escutar os arquivos? Estão abertos a dialogar e a compreender as demandas dos arquivos, de absorver as necessidades dos arquivos?

CR: Idealmente é isso que deveria acontecer. É preciso que isso aconteça. Eu não estava presente, mas recentemente a Comissão Técnica da FIAF teve um encontro com fabricantes de escâners em Amsterdam. Isso está dentro, justamente, de uma tradição da Comissão Técnica. Quando houve toda a questão sobre a desbotamento dos filmes, de salvaguarda dos sons magnéticos, etc. Os membros da comissão tiveram encontros regulares com fabricantes de películas, com fabricantes de fitas magnéticas, para compreender, para chagar a um entendimento de como conservar a cor ou o magnético. Precisamos continuar nesse sentido. No momento atual, os consultores de soluções de arquivamento estão realmente a escuta dos arquivos. Não podemos ter apenas uma perspectiva comercial, pois em todos os sentidos isso vai virar qualquer coisa. Precisamos verdadeiramente encontrar soluções perenes, inteligentes, possivelmente baratas e que sejam acessíveis. Isso seria o ideal para o futuro da preservação.

Bibliografia:

BARBIN, Pierre. La Cinémathèque Française. Inventaire e legends (1936-1986). Paris:Vuibert, 2005.

COELHO, Maria Fernando Curado. A experiência brasileira na conservação de acervos audiovisuais: um estudo de caso. Dissertação (Mestrado em Ciências da Comunicação), Escola de Comunicação e Artes da Universidade de São Paulo (USP), São Paulo, 2009.

COMTE, Christian; RICORDEL, Nicolas. SACHA: un scanner spécifique pour les films anciens aux Archives Françaises du Film. Journal of Film Preservation. Bruxelas, Dez. 20104.

MANNONI, Laurent. Histoire de La Cinémathèque Française. Paris: Gallimard, 2006.

LE ROY, Eric. Cinémathèques et archives du film. Paris :Armand Colin, 2013.

OLMETA, Patrick. La Cinémathèque française de 1936 à nos jours. Paris: CNRS, 2000. (CNRS histoire. Histoire contemporaine).

PAINI, Dominique (dir.) Le musée imaginaire d'Henri Langlois. Paris: Flammarion; La Cinémathèque française, 2014.

SCIENCE AND TECHNOLOGY COUNCIL OFTHE ACADEMY OF THE MOTION PICTURES ARTS AND SCIENCES. O Dilema Digital. Cinemateca Brasileira, 2009.

SITTON, Robert. Lady in the dark: Iris Barry and the art of film. Nova Yorque: Columbia University Press, 2014.

WASSON, Haidee. Museum Movies: the Museum of Modern Art and the birth of art cinema. Berkeley e Los Angeles: University of California Press, 2005. 